\title{
O PAPEL DO DESIGN NA PRODUÇÃO E CULTURA DO ARTESANATO COM TEARES E CORANTES NATURAIS DE CARMO DO RIO CLARO-MG/ FURNAS
}

The role of design in production and culture of crafts with natural dyes and looms of Carmo do Rio Claro-MG/FURNAS

\author{
IAMAMURA, Patrícia Nascimento I Mestranda em Têxtil e Moda \\ Universidade de São Paulo - EACH/USP \\ patty_famopa@yahoo.com.br
}

\section{KANAMARU, Antonio Takao I Doutor em Design}

Universidade de São Paulo - FAU/USP

kanamaru@usp.br

\begin{abstract}
Resumo
Neste estudo propôs-se como objetivo geral analisar teoricamente o papel do design na produção e cultura do artesanato popular. Enfocou a criação de superfícies têxteis populares e o respectivo papel do design no processo de coleta e análise de corantes naturais nativos, para a produção de tecelagens regionais, da cidade de Carmo do Rio Claro-FURNAS. Como procedimento geral, a literatura para o mapa e documentação de espécies vegetais locais, foi revisada, tradicionalmente utilizados para obtenção de corantes e aplicação em tecelagem. Em sequência realizou observações em campo e empregou também entrevistas com aplicação de questionário para a compreensão dos usos populares dessa matéria-prima entre artesãos locais. Como resultados de análise, observou o caráter sustentável desse processo e a sua relevância para a preservação da identidade cultural local e regional.
\end{abstract}

Palavras-Chave: Design de superfície têxtil. Design. Corantes naturais. Artesanato.

\section{Abstract}

In this study, it was proposed a general objective theoretically analyze the role of design in production and culture of folk crafts. Focused on the creation of popular textile surfaces and their role in the design process of collection and analysis of native natural dyes for the production of regional weavings, the city of Carmo do Rio Claro-Furnas. As a general procedure to map the literature and documentation of local plant species, was reviewed, traditionally used to obtain dyes and weaving application. Sequentially conducted field observations and interviews also employed a questionnaire to understand the popular uses of this raw material from local artisans. The results of analysis showed the sustainable nature of this process and its relevance to the preservation of local and regional cultural identity.

Key-words: Surface design textile. Design. Natural dyes. Crafts. 


\section{INTRODUC̣ÃO}

Ao analisar o design no sentido interdisciplinar e seus campos de atuação, observa-se a sua relevância também em relação ao mundo do artesanato popular em contexto e às necessidades de desenvolvimento econômico e cultural brasileiro.

Conforme Aluísio Magalhães "O valor de uma ação se mede no tempo e se insere no processo histórico, não apenas pela sua duração temporal, mas também pela relação entre esta duração e a intensidade da atuação" (MAGALHÃES, 1998, p. 9).

Nesse sentido, o artesanato popular é abordado em seu sentido mais dinâmico e complexo relacionado ao modo de produção, bem como de identidade cultural.

Embora o design seja relacionado à produção industrial, procurou sustentar uma abordagem baseada na perspectiva crítica do autor. Nesse sentido Magalhães (1998, p. 11-12) destacou a necessidade de "[...] enfatizar o caráter interdisciplinar do desenho industrial'. Trata-se de uma atividade contemporânea e, como tal nasceu da necessidade de estabelecer uma relação entre diferentes saberes $[\ldots . .]^{\prime \prime}$.

Propôs-se, como primeira delimitação, a área têxtil e de moda como campo de estudo do projeto de pesquisa em questão. Como afirma Berlim (2012, p. 26):

Moda é um conceito multifacetado e multidisciplinar Multifacetado porque é um fenômeno constituído de várias possibilidades de estudo, todas interligadas e quase sempre interdependentes. [...]. É decorrente de um complexo campo de estudo, formado por disciplinas que fundamentam o produto - como agricultura, engenharia, química, design e seus atributos - e os processos produtivos - como tecnologia têxtil, tecnologia em geral, modelagem, desenho, tingimento, gestão e logística - com disciplinas que fundamentam o desejo, o consumo e as tendências como história, psicologia, semiótica, as artes em geral e, sobretudo, a comunicação.

$1 \quad$ O autor Aloísio Magalhães utiliza a expressão oficial "desenho industrial" dominante até fins do século XX no Brasil. Para fins de padronização terminológica mais atual, consideramos a expressão design já dicionarizada em língua portuguesa. 
Embora técnicas industriais tornaram-se dominantes nas primeiras décadas do século $X X$ e, consequentemente, é possível identificar na atualidade a necessidade, reconhecimento e valorização de antigas técnicas artesanais, considera-se nesse processo histórico, econômico e cultural, assim, a necessidade de uma abordagem mais adequada, que proporcione condições para a investigação que integre os modos de produção com vistas também aos novos requisitos atuais de sustentabilidade, responsabilidade social e identidade cultural.

No entanto, Adélia Borges na obra Design + Artesanato, afirma que no Brasil as atividades de artesanato e design sempre viveram em mundos separados.

\begin{abstract}
A institucionalização do design no Brasil foi feita a partir da ruptura com o saber ancestral manifesto em nossa cultura material [...]. O desejo deliberado de abolir o objeto feito à mão em prol do feito à máquina obedeceu à visão de que a tradição da manualidade era parte do passado de atraso, subdesenvolvimento e pobreza, que o futuro promissor proporcionado pelas máquinas nos faria superar [...]. (BORGES, 2011, p. 31).
\end{abstract}

Nesse contexto, no design do Brasil durante a década de 60, embora fortemente enviesado pela racionalidade técnica-industrial europeia, sobressaem-se dois pesquisadores, entre eles Aloísio Magalhães e também Lina Bo Bardi, que procuraram revisar criticamente essa influência de modo a contextualizar o design e pensar a originalidade do brasileiro.

Lina, natural da Itália, voltou sua investigação da cultura material artesanal popular para analisar as raízes da identidade brasileira. Segundo a qual

Essa parte da humanidade, levada pelas necessidades a
resolver por si mesma o próprio problema existencial e
não possuindo esta pseudocultura, tem a força necessária
ao desenvolvimento de uma nova e verdadeira cultura.
Esta força latente existe em alto grau no Brasil, onde uma
forma primordial de civilização primitiva (não no sentido
de ingênua, e sim composta de elementos essenciais, reais
e concretos) coincide com as formas mais avançadas do
pensamento moderno. (BARDI apud BORGES, 2011, p. 35).

Tanto Lina Bo Bardi quanto Aloísio Magalhães, influenciados por Mário de Andrade, consideraram a relevância do artesanato popular brasileiro 
como portadores dos fundamentos e expressão da originalidade da produção cultural material brasileira. Daí a importância da pesquisa em design abordar primordialmente a produção artesanal da cultura material popular brasileira para um real desenvolvimento moderno do design nacional e a sua adequação ao meio.

Para uma noção mais articulada do artesanato popular como fenômeno cultural complexo, Júlio Roberto Katinsky define artesanato como

"[...] modos de produção de bens que se diferenciam do modo padrão de produção de bens de nossa sociedade, isto é, a indústria maquinizada e automatizada, veremos que ele cobre uma infinidade de campos da atividade humana". (KATINSKY, 2008, p. 1).

Nesse sentido, procurou superar o equívoco dominante evolucionista e positivista desde o século XIX, da industrialização como etapa superior da produção e o artesanato como estágio rudimentar e decadente. Segundo ele, "Está muito difundida a crença de que o artesanato é uma atividade marginal e em processo de desaparecimento [...]". (KATINSKY, 2008, p. 1).

Sustenta, assim, o papel do design na produção e cultura artesanal popular, evitando a abordagem fossilizada desse modo de produção e cultura, em geral associada equivocadamente como repetição e não criação social e dinâmica em comunidades e ambientes.

\section{O papel do Design na produção do Artesanato Local}

Uma vez consciente da abordagem e, foi relatado método o recorte e respectivo mapa a coleta de dados e análise baseado em tecelagens localizadas na cidade de Carmo do Rio Claro, situado no estado de Minas Gerais. Geograficamente, é indicado que "[...] o município de Carmo do Rio Claro está localizado na Mesorregião do Sudoeste Mineiro e na Macrorregião de Furnas. A área do município é de $1086 \mathrm{~km}^{2}$ (estão incluídos $221 \mathrm{~km}^{2}$ de terras inundadas), que formam o grande lago de Furnas". (HORVÁTH, 2008, p. 13).

Localização cartográfica da cidade de Carmo de Rio Claro-FURNAS, em vermelho: 
Figura 1 - Carmo de Rio Claro-FURNAS

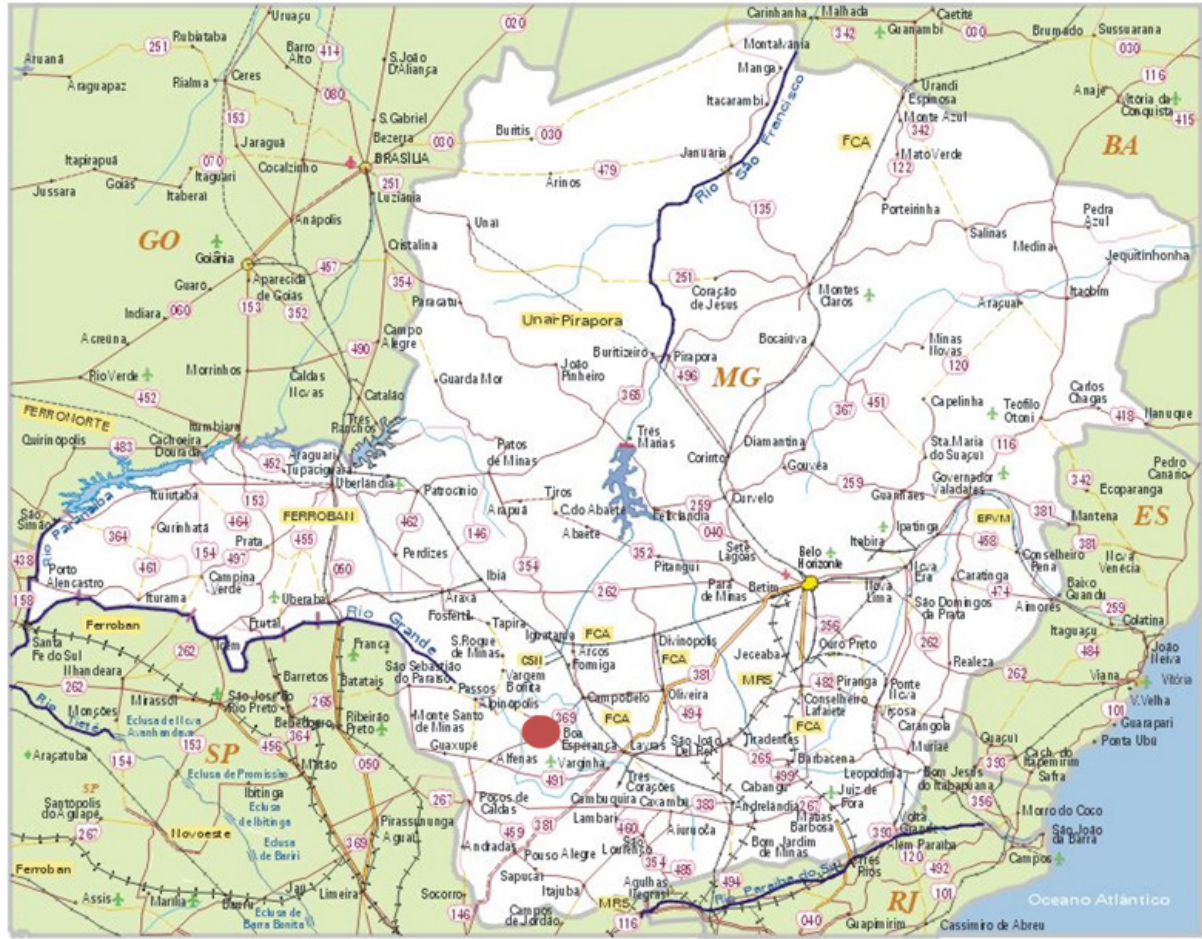

Fonte: Mapa... (2012).

$\mathrm{Na}$ atualidade a população da cidade é composta por 20.426 habitantes, distribuídos em $1065 \mathrm{~km}^{2}$ de extensão territorial, segundo dados em censo oficial (IBGE, 2010).

Observou que historicamente por tradição e resistência se desenvolveu nesta cidade a produção de tecelagem manual. Como afirma Ferreira (1995, p. 282):

[...] A tecelagem sempre foi uma das atividades predominantes tanto na cidade como nas fazendas, desde o tempo da escravidão [...] essa tradição é hoje desenvolvida por quase toda a comunidade de Carmo do Rio Claro nos seus mais diversos níveis sociais.

E o trabalho do tecelão na cidade abrange por todas as etapas de produção, desde a obtenção da matéria-prima natural, como algodão e lã, à fiação e tingimento com corantes naturais, até a tecelagem propriamente dita.

No ano de 1840, Carmo do Rio Claro já era um povoado próspero, a produção artesanal passa a existir. Os artesãos teciam em teares manuais e quase todas as moradias. Os fios eram extraídos do algodão ou do carneiro. Depois o 
processo de tintura, usando-se raízes, cascas ou folhas do Ipê, coqueiro, argila, pau-brasil, quaresminha, etc. A tecelagem sempre foi uma das atividades predominantes na cidade como nas fazendas, desde o tempo da escravidão. Dona Anésia, a mais antiga artesã em atividade em Carmo do Rio Claro é a principal precursora da tecelagem artesanal em tear manual. (HORVÁTH, 2008, p. 32-33).

Finalmente, observou que a cidade conta com aproximadamente 30 tecelagens em funcionamento (CARMO DE RIO CLARO. Prefeitura Municipal, 2013), que compõem a principal fonte de trabalho e renda citadina e regional. Em hipótese, considerou o papel decisivo do design em abordar essa produção e cultura ressaltando-se a sua originalidade e identidade. Contempla estrategicamente a necessidade de resgatar o processo de tingimento natural, mas antes refletiu sobre a complexidade da relação entre técnica e cultura comunitária, estrategicamente importante para o município referido, bem como para cidades adjacentes.

\section{Tramas sociais do fazer artesanal da tecelagem popular}

Como relato da investigação com procedimentos de observação in loco e entrevistas, constatou a necessidade da preservação dos teares manuais e do resgate da utilização dos corantes naturais não apenas como raciocínio a priori, mas como constante manifestação de tecelões e moradores da cidade. A preocupação é latente, principalmente sobre a preservação dessa forma de produção como saída para se manter a identidade cultural local e também, do artesanato popular local-regional.

Ao mesmo tempo, certificou como ética da restituição de resultados de pesquisa científica, que a preservação da produção artesanal constitui aspecto essencial do trabalho. Portanto, verificou a coerência de revisão da literatura. Mas também com o avanço específico relacionado ao desenvolvimento da cultura material.

Borges (2011) relata o problema comum de trabalhos de estilistas e outros designers e demais pesquisadores, que se apropriam dos conhecimentos e mão de obra em comunidades populares, sem nenhuma restituição de resultados e socialização de benefícios sociais entre sujeitos da pesquisa. Para a autora, "[...] o difícil é fazer com que esse trabalho tenha significado e relevância para a comunidade local e, assim, possa ser continuado". (BORGES, 2011, p. 139). 
O artesanato foi analisado considerando o sujeito da pesquisa, o artesão, de modo a cumprir o papel ético-científico do design.

Para um aprofundamento dessa consciência de pesquisa, buscou o conceito de prática artesanal no Brasil, que embora seja conhecida como artesanato, Lina Bardi (1994) e Aloísio Magalhães (1997) definiram como um "pré-artesanato".

[...] O Brasil se industrializou, a nova realidade precisa ser aceita para ser estudada. A volta a corpos sociais extintos é impossível, a criação de centros artesanais, o retorno a um artesanato como antídoto a uma industrialização estranha aos princípios culturais do país é errada. Porque o artesanato como corpo social nunca existiu no Brasil, o que existiu foi uma imigração rala de artesãos ibéricos ou italianos e, no século XIX manufaturas. O que existe é um pré-artesanato doméstico, esparso, artesanato nunca. (BARDI, 1994, p. 12).

E Aloísio Magalhães (1997, p. 181) acrescenta:

$\mathrm{Na}$ realidade penso que, dentro do conceito clássico e ortodoxo, não existe propriamente artesanato no Brasil. O que parece existir é uma disponibilidade imensa para o fazer, para a criação de objetos [...] e talvez seja preciso ter a coragem de dizer que não existindo as tradições profundas de cristalização do trato de matéria-prima que constitui formas artesanais clássicas, o que nós temos é que observar essa disposição, essa presença muito alta do índice de invenção.

Focou, assim, na "invenção" ou no sentido como foi defendido, na criação popular como ênfase conceitual e objeto central na investigação. Empiricamente apoiou em estudo focado ao caso da principal artesã em tecelagem da localidade, considerada pioneira na região, Dona Anézia, cuja experiência abrange toda a cadeia têxtil da produção em pequena escala, desde o plantio do algodão ou a criação de ovelhas para a extração da lã até a fiação e posterior aplicação de corantes naturais. Esse conhecimento e tradição do fazer manual da fibra, tingimento e tecelagem, representa influência geral na cidade e região.

No entanto, nesse mesmo espaço, observou que recursos industriais também estão dinamicamente presentes em todo esse processo devido ao caráter complexo das necessidades econômicas e sociais locais. 
Não obstante a esforços na preservação da produção artesanal observase a troca de teares $100 \%$ artesanais por semi-industriais, devido à demanda que conduz ao aumento da produção e à necessidade de redução de custos. Nesse aspecto, deparou-se com esse paradoxo do artesanato popular.

Verifica nesse processo a contribuição do design com a elaboração criativa de motivos com maior riqueza de detalhes e a expressão formal da cultura local.

Quanto a esses elementos de identidade na linguagem visual, Aloísio Guimarães observou a obra de um artista mineiro chamado Edmar de Almeida, que pesquisou padrões de tecidos feitos em tecelagem artesanal na região do Triângulo Mineiro, com ajuda de Lina Bo Bardi e Flávio Império. (BORGES, 2011). Segundo o qual, "[...] seu interesse era fazer um inventário e codificar os padrões dos repasses para devolvê-los às próprias artesãs, contribuindo assim para registrar seu saber e aumentar seu repertório. (BORGES, 2011, p. 40)

Com o apoio do CNRC (Centro Nacional de Referência Cultural), resultados desse projeto foram publicados, o que contribuiu muito para a vida e trabalho dos artesãos, onde desenhos das padronagens foram realizados com auxílio da computação gráfica.

Para Adélia Borges, esta afirma que fora "[...] uma forma de devolver às comunidades, elaborado e enriquecido, seu próprio patrimônio cultural"(BORGES, 2011, p. 41). Para a mesma autora,

O levantamento cultural do pré-artesanato brasileiro poderia ter sido feito antes de o país enveredar-se pelo caminho do capitalismo dependente, quando uma revolução democrático-burguesa ainda era possível, nesse caso, as opções culturais do campo do desenho industrial poderiam ter sido outras, mais aderentes às necessidades reais do país [...]. O Brasil abandona a opção da grossura e escolhe a finesse. (BARDI apud BORGES, 2011, p. 41).

Tendo como pressuposto a inventividade, a criação popular brasileira, em lugar do refinamento desenraizado, apesar de sua rusticidade, é considerado o potencial do desenvolvimento formal e visual da tecelagem junto com a tradição técnica manual da tecelagem local. A abordagem do design em sua interdisciplinaridade e necessidade de trabalho coletivo constitui a própria forma essencial do trabalho comunitário. 
Considera-se, historicamente, o uso de corantes naturais nativos sob o ponto de vista da sustentabilidade nessa produção e a importância de resgate de espécies e técnicas de aplicação em fibras. Esse uso permite aos artesãos adquirir cores vivas e diferentes a um custo mais baixo e o aproveitamento de matérias-primas disponíveis no ambiente local em si revela a sua racionalidade e o fortalecimento da participação popular. Para Borges (2011, p. 79),

\begin{abstract}
Outra vertente entre os caminhos possíveis nas ações de revitalização do artesanato brasileiro diz respeito ao aproveitamento das potencialidades dos materiais encontrados nas regiões. Nesse quesito, certamente, os designers e os técnicos letrados têm mais a aprender com os artesãos e moradores locais do que o contrário.
\end{abstract}

O esgotamento dos recursos naturais tem sido uma das preocupações constantes na sustentabilidade, razão pela qual o resgate do uso de corantes naturais locais e regionais adquire maior relevância, por isso sugere-se que após a descoberta de corantes naturais, os mesmos devam ser cultivados para fins de extração.

Tony Fry (2011), em sua obra Facing Finitude, expõe algumas implicações da insustentabilidade, como por exemplo, desastres ecológicos, esgotamento das fontes naturais e o aumento de refugiados ambientais, que são aquelas pessoas que após terem sofrido com catástrofes da natureza, ficam sem lugar para viver.

E então alerta para um novo paradigma econômico de iniciativa políticoeconômica para um pensamento e reflexão crítica, pois ele afirma que com a Revolução Industrial as pessoas passaram a consumir desenfreadamente, e que o movimento por ele nomeado de Defuturing, acontece muitas vezes sob a máscara do belo e elegante (FRY, 2011).

Fry (2011) critica ainda a maioria dos arquitetos e designers que continuam a ser acríticos prestadores de serviço para uma sociedade cada vez mais consumista.

Mas a produção artesanal local e regional de Carmo de Rio Claro demonstra nos resultados que o equilíbrio entre meios na economia local, preservação ambiental e esforço pela manutenção e construção da identidade social, constitui em si caso por excelência de sustentabilidade ambiental e social.

Para Fletcher e Grose (2011), 
A cor é um dos fatores mais importantes na venda de uma peça, porém nos processos de tingimento industriais é a natureza que fornece seus "recursos" para abastecerem as tecelagens, como por exemplo, no mundo todo estima-se que a indústria têxtil usa 378 bilhões de litros de água por ano. (FLETCHER; GROSE, 2011, p. 37).

Nesse sentido, o uso de corantes naturais auxiliam a minimizar o descarte de poluentes relacionados a beneficiamentos químicos em águas, importante para cidades interioranas brasileiras.

De acordo com Berlim (2012) em levantamento de dados para a Associação Brasileira de Indústria Têxtil e de Confecção (ABIT), a indústria têxtil brasileira com histórico de aproximadamente 200 anos, é o quarto maior parque produtivo de confecção têxtil do mundo e o quinto maior produtor mundial. É o único país do Ocidente que possui uma cadeia têxtil completa, desde lavradores de fibras a top models. Além disso, é o segundo maior produtor e o terceiro maior consumidor de denin ${ }^{2}$ do planeta. Em relação ao algodão, a produção é de 1,5 milhões de toneladas anuais. Financeiramente, aponta que

\begin{abstract}
O faturamento da cadeia têxtil e de confecção brasileira é estimado em U\$2,5 bilhões. O setor é o segundo maior empregador da indústria de transformação no país, compreendendo mais de 30 mil empresas e gerando anualmente 1,7 de empregos diretos. Ainda de acordo com a $\mathrm{ABIT}$, além dos empregos diretos, o setor gera renda indireta para 8 milhões de trabalhadores, sendo 75\% dessa mão de obra feminina. (BERLIN, 2012, p. 29).
\end{abstract}

Diante desse quadro, pode-se considerar o impacto dessa produção e consumo em grandes capitais no aspecto do tingimento industrial. Assim nichos relacionados à produção local e regional interiorana relacionada aos processos de tingimento artesanais a partir de espécies tradicionais em ocorrências e práticas autóctones, neste caso, geram resíduos menos "agressivos" ao ambiente, podendo ser descartados e tratados em represas artificiais construídas para este fim, que posteriormente poderiam ser usadas para irrigar as plantações de vegetações de onde os corantes seriam extraídos.

Objeção técnica nesse processo pode ser verificada, no entanto, na 2 Segundo Chataignier (2006, p. 144) originalmente coutil ou cutil (fr.) fabricado em Nimes, na França. Tingido em azul índigo (anil). Denim é corruptela de azul de Nimes. Pezzolo (2007, p. 299) indica "Serge de Nimes". Para Marsh e Trynka (2003, p. 55) nesse tecido somente os fios da urdidura são tingidos e sua classificação técnica ocorre por peso. 
estabilidade da cor a partir de corantes naturais em fibras para tecelagem. Mas segundo Fletcher e Grose,

[...] A estabilidade da cor ao longo do tempo, sobretudo em fibras de celulose, também é uma preocupação constante. Mas para muitos dos que optam pelo tingimento natural, essas objeções desconsideram o que é realmente importante. Com corantes naturais o propósito em geral não é atender aos padrões que a indústria impõe a si mesma, mas, acima de tudo, trabalhar dentro dos limites da natureza e adaptar a criatividade e prática conforme necessário. (FLETCHER; GROSE, 2011, p. 43).

Corantes naturais antes depreciados em indústria têxtil, com a busca pela sustentabilidade, tornaram-se mais valorizados tanto por produtores, distribuidores e consumidores como valor agregado e ético:

[...] Hoje, com o crescente interesse por sustentabilidade, inovações técnicas começam a diluir as diferenças entre objetivos industriais e artesanais, e entre o que é corante natural e o que é corante sintético. Mais plantas cultivadas por hectare e mais extrato produzido por planta começam de novo a impor sobre a natureza metais industriais de interesse humano. A aceitação de avanços técnicos em corantes naturais exigirá de nossa aguçadas capacidades cognitivas a avaliação de seus perfis de sustentabilidade, com medições que considerem mais do que seu caráter "natural". (FLETCHER; GROSE, 2011, p. 43).

Nesse sentido geral, reputa-se o caso da tecelagem popular de Carmo do Rio Claro, o uso de corantes e o seu indissociável caráter sustentável socioambiental, pedagógico para a produção e cultura material local e regional, onde se integra o trabalhador e comunidade artesã, com preservação ambiental e uma cultura material baseada na criação coletiva onde também se revela a identidade como elemento estruturador e não apenas como valor secundário a agregar.

\section{CONSIDERAC̣ÕES FINAIS}

Ao analisar o design na produção e cultura artesanal têxtil no referido 
caso de Carmo do Rio Claro-FURNAS (MG), é possível considerar a relevância dessa disciplina de projeto dada a possibilidade metodológica e interdisciplinar inerente ao design diante das necessidades de produção, desenvolvimento e circulação do artesanato têxtil sem descaracterizar os fundamentos socialmente includentes e preservacionistas da cultura manufatureira do artesanato têxtil local e regional. Desse modo, é considerado o caráter decisivo dessa abordagem especializada diante da complexidade da produção e cultura artesanal têxtil que não se restringe apenas à tradição ou à distribuição comercial, mas sim ao mundo das relações sociais e ambientais, de produção e cultura local e regional, fundadas em valores essenciais como identidade cultural, responsabilidade social e equilíbrio sustentável.

\section{REFERÊNCIAS}

BARDI, Lina. Tempos de grossura: O design no impasse. São Paulo: Instituto Lina Bo e P. M. Bardi, 1994.

BERLIM, Lilyan. Moda e sustentabilidade: uma reflexão necessária. São Paulo: Estação das Letras e Cores, 2012.

BORGES, Adélia. Design + artesanato: o caminho brasileiro. São Paulo: Terceiro Nome, 2011.

CARMO DE RIO CLARO. Prefeitura Municipal. Serviços. Carmo de Rio Claro, 2013.

CHATAIGNIER, Gilda. Fio a fio: tecidos, moda e linguagem. São Paulo: Estação das Letras, 2006.

FERREIRA, Celeste Noviello. O quadro de saudades: Carmo do Rio Claro. Três Corações: Excelsior, 1995.

FLETCHER, Kate; GROSE, Lynda. Moda e sustentabilidade: design para mudança. São Paulo: SENAC, 2011.

FRY, Tony. Facing finitude. In: . Design as politics. New York: Berg, 2011. p. 21-46.

HORVÁTH, Eugen Emmerich. A pequena notável I - Carmo do Rio Claro: cento e trinta anos de emancipação política 1887-2007. Carmo do Rio Claro, MG: O Artesanal, 2008. 
IBGE. Censo Demográfico. Contagem Populacional. Rio de Janeiro, 2010.Disponível em:<http://cidades.ibge.gov.br/painel/populacao. php?lang $=\&$ codmun $=311440 \&$ search=minas-gerais $\mid$ carmo-do-rioclaro|infograficos:-evolucao-populacional-e-piramide-etaria>. Acesso em: 20 jun. 2012.

KATINSKY, Júlio Roberto. Artesanato moderno. Revista Brasileira de Design, São Paulo, ano 1, n. 1, 2008. Disponível em: <http://www.agitprop.com.br/index.cfm?pag=repertorio_ det\&id=5\&titulo=repertorio $>$. Acesso em: 15 ago. 2012.

MAGALHÃES, Aloisio. E triunfo: a questão dos bens culturais no Brasil. Rio de Janeiro: Nova Fronteira, 1997.

MAGALHÃES, Aloísio. O que o desenho industrial pode fazer pelo país? Arcos, Rio de Janeiro, v. 1, p. 9-13, 1998.

MAPA Rodoviário de Minas Gerais. Disponível em: <http://www. mapas-mg.com/mapa-rodoviario.htm>. Acesso em: 9 dez 2012.

MARSH, Graham; TRYNKA, Paul. Denim, l'épopée illustrée d'un tissu de legende. Paris: Ed. du Collectionneur, 2003.

PEZZOLO, Dinah Bueno. Tecidos: história, tramas, tipos e usos. São Paulo: Senac, 2007.

Recebido em :30/09/2012. Aceito em: 15/03/2013. 


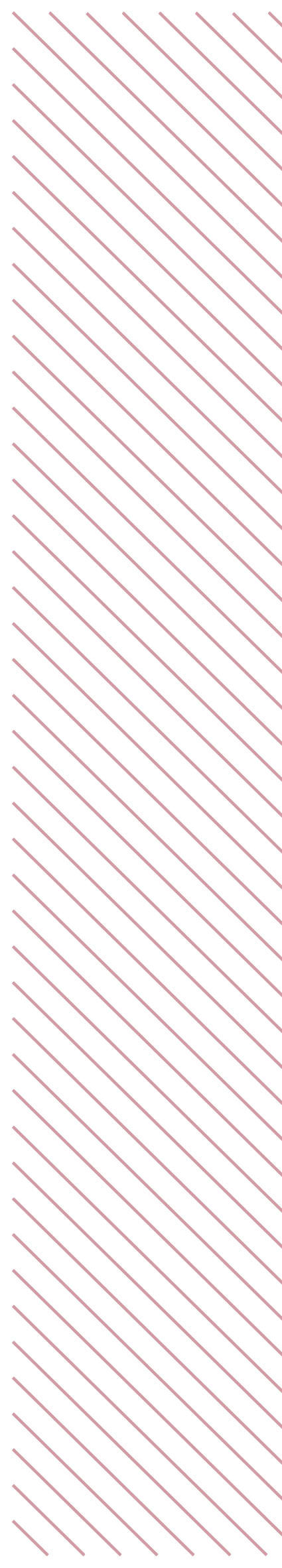

